\title{
Apoptosis for HepG2 Cells Induced by Low-frequency and Low-power Ultrasound with Hydroxyapatite
}

\author{
Chen Chen ${ }^{\mathrm{a}}$, Tian Xü ${ }^{\mathrm{b}}$, Weiwei Wang ${ }^{\mathrm{c}}$, Li Li ${ }^{\mathrm{d}}$, Wei Wu $\mathrm{Wu}^{\mathrm{e},}$ \\ Key Laboratory of Environmental Medicine and Engineering, Ministry of Education, School of \\ Public Health, Southeast University, Nanjing, 210009, China \\ a915666024@qq.com, b354158142@qq.com, c1715556404@qq.com, d1404157708@qq.com, \\ e corresponding author101005800@seu.edu.cn
}

Keywords: low-frequency and low-power ultrasound, hydroxyapatite, apoptosis.

\begin{abstract}
The exploration of the apoptosis for HepG2 cells induced by low-frequency and low-power ultrasound combined with hydroxyapatite, provides data base for future clinical treatment. In this research, we selected the HepG2 cells model. The experiences were divided into four groups: control group, ultrasound group, hydroxyapatite group, and ultrasound + hydroxyapatite group. Ultrasound group and control group replaced the normal culture medium, hydroxyapatite group and ultrasound + hydroxyapatite group replaced culture medium containing hydroxyapatite. The control group and hydroxyapatite group were not treated, while ultrasound group and ultrasound + hydroxyapatite group were treated by ultrasound with different parameters $\left(f=20 \mathrm{kHz} ; \mathrm{P}=0.1,0.2,0.3 \mathrm{w} / \mathrm{cm}^{2} ; \mathrm{t}=30,60,90\right.$, $120,150,180 \mathrm{~s} ; \mathrm{T}=0,12,24,48,72 \mathrm{~h})$. MTT test and flow cytometry detected the inhibitory rate of the cells, cell apoptosis and cell cycle. MTT experiment results show that ultrasound with different parameters stimulates the cell model, which leads to the difference of the inhibition rate of cell growth. Among them, the inhibition rate of cell growth reached the top value $(71.726 \pm 0.677) \%$ with the treatment of $f=20 \mathrm{kHz}, \mathrm{P}=0.2 \mathrm{w} / \mathrm{cm}^{2}, \mathrm{t}=90 \mathrm{~s}, \mathrm{~T}=48 \mathrm{~h}$. There was a statistical significance compared with the control group, ultrasound group, and hydroxyapatite group $(P<0.05)$. Under such condition, the apoptosis rate of HepG2 cells was a statistically significant change compared with the control group, ultrasound group, and hydroxyapatite group $(P<0.05)$. During the cell cycle assay, the ultrasonic + hydroxyapatite group also showed obvious $\mathrm{G} 2 / \mathrm{M}$ phase block. Low frequency and low-power ultrasound with Hydroxyapatite induced the apoptosis in human HepG2 cells.
\end{abstract}

\section{Introduction}

Hepatocarcinoma (HCC) is one of the most frequently occurring clinical disease, which has been a serious public health problem to threaten human life safety [1]. Surgical operation is one of the main therapy for liver cancer. However, it has many side effects. For example, the postoperative five-year survival rate is low and the quality of life of patients is not improved [2, 3, 4].

Ultrasound (US) is a non-invasive diagnosis tool which has been used in clinic. Moreover it has therapeutic applications, including ultrasound-guided drug and gene delivery [5]. Ultrasound can generate pores on cell membrane and then change its permeability. This process is called sonoporation. In the early studies, it found that ultrasound with frequency of 20 kilohertz $(\mathrm{kHz})$ can change cell membrane permeability, promoting the drug, gene, and others macromolecular substances into cell to therapy [6]. Studies showed that Low frequency and low-power ultrasound can promote exogenous substance in cells, and induce the apoptosis of them. There is a positive correlation between the cell mortality and the intensity of ultrasound. High power ultrasound can kill cancer cells and normal cells. Low power ultrasound just act on tumor cells $[7,8]$. The paper reaches a conclusion that normal cells have better resistance to low-frequency ultrasound, while malignant tumor cells are more sensitive to low-frequency ultrasound [9].

Hydroxyapatite (HA) is the principal inorganic component of human bones and teeth. The artificial HA is similar to the body's own HA with an excellent biocompatibility, bioactivity, biodegradability and non-immunogenicity $[10,11,12,13]$. HA has been wildly used in medicine for bone substitutes, and drug carriers. Additionally, in early stage, researcher found that $\mathrm{HA}$ also has anti-tumor effect in 
vivo and vitro [14, 15]. Research suggests that the inhibitory of HA had dose-dependent manner, which was better with the increasing of HA concentration. However, another paper points out that with the increasing of HA concentration, it not only inhabited the hepatocarcinoma cell, but also caused damage to hepatocyte [16].

In this study, low-frequency and low-power ultrasound combined with Hydroxyapatite was used to induce apoptosis of tumor cells, and to help explore the apoptosis mechanism. The purpose of this study is aimed to propose a safer, non-invasive, and non-harmful side-effects approach in cancer therapy, which provides data base for future clinical treatment.

\section{Materials and methods}

\subsection{Cell culture}

Human HepG2 cells were grown in cell culture bottle, cultured in DMEM medium with 10\% fetal bovine serum. Cells were placed in incubator at $37^{\circ} \mathrm{C}$ in a humidified atmosphere of $5 \% \mathrm{CO}_{2}$. When grown to $70-80 \%$, cells were collected which were seeded into 12 -well plates at a density of $3 \times 10^{5}$ cell $/ \mathrm{ml}$.

\subsection{Hydroxyapatite characterization}

Hydroxyapatite particles were analyzed by X-ray diffraction (XRD) and evaluated by scanning electron microscopy (SEM) which studied the morphology of particles. Hydroxyapatite particles were weighed and sterilized, then put into the medium with ultrasonic agitation where hydroxyapatite particles concentration was $200 \mu \mathrm{g} / \mathrm{ml}$ before the experiment began.

\subsection{Ultrasound treatment}

The ultrasonic with different parameters $\left(\mathrm{f}=20 \mathrm{kHz} ; \mathrm{P}=0.1,0.2,0.3 \mathrm{w} / \mathrm{cm}^{2} ; \mathrm{t}=30,60,90,120,150\right.$, $180 \mathrm{~s} ; \mathrm{T}=0,12,24,48,72 \mathrm{~h}$ ) were selected by the preliminary experiment and the FDA regulations.

\subsection{Cytotoxicity assay}

MTT assay was used to evaluate the HepG2 cell toxicity. Cells were treated by hydroxyapatite concentration $200 \mu \mathrm{g} / \mathrm{ml}$ and different ultrasonic parameters. MTT was joined into each well incubated at $37^{\circ} \mathrm{C}$ for $4 \mathrm{~h}$. The medium was replaced with DMSO to dissolve the formazan crystals. Then absorbance at $570 \mathrm{~nm}$ was measured by microplate reader and calculated the inhibition rate of cell growth.

\subsection{Apoptosis Assay}

Cells were collected into EP tubes, washing twice by PBS. Cells apoptosis was measured by Annexin V-FITC/PI kit, using flow cytometer.

\subsection{Flow Cytometry Analysis of Cell Cycle}

Cells were collected into EP tubes, washed twice by PBS. The EP tubes were added $70 \%$ alcohol $500 \mu \mathrm{l}$ and fixed overnight. Then according to the kit, we used the flow cytometer to test the cell cycle.

\subsection{Statistical Analysis}

All data was set up data base by Excel and analysed by SPSS19.0. Quantitative values were expressed as Mean \pm SD. Statistical differences between groups were examined using ANOVA. $P<$ 0.05 was considered as statistically significant.

\section{Results}

\subsection{Hydroxyapatite characterization analyses}

SEM Morphology and XRD pattern of hydroxyapatite particles were shown in Fig. 1. Hydroxyapatite particles showed rod-like morphology, and nano-sized is uniform at 50x100nm. It was dispersed at medium after ultrasonic agitation. The XRD pattern of HA had a good match with the standard both in terms of intensity and positions of the peaks. It can be confirmed that the particles were hydroxyapatite. 


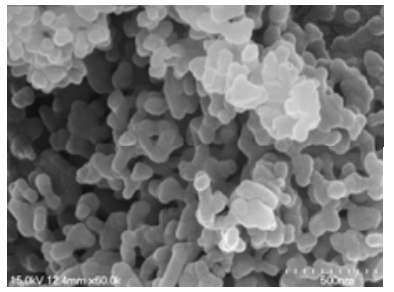

(a)

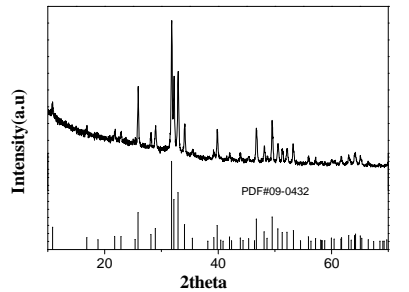

(b)

Fig. 1 SEM Morphology (a) and XRD pattern (b) of hydroxyapatite particles

\subsection{The inhibition rate of cells growth analyses}

The inhibition rate of cells growth were shown in Fig. 2. As shown in figure, the cells were treated with different ultrasound parameters with hydroxyapatite particles, and the inhibition rates of cells growth were different. In general, US+HA groups treated the cell which the inhibition rates of cells growth were prior to other groups. Especially, the inhibition rate of cell growth reached the top value $(71.726 \pm 0.677) \%$ with the treatment of $f=20 \mathrm{kHz}, \mathrm{P}=0.2 \mathrm{w} / \mathrm{cm}^{2}, \mathrm{t}=90 \mathrm{~s}, \mathrm{~T}=48 \mathrm{~h}$. It was statistically significant compared with that for control group, ultrasound group, and hydroxyapatite group $(P<0.05)$.

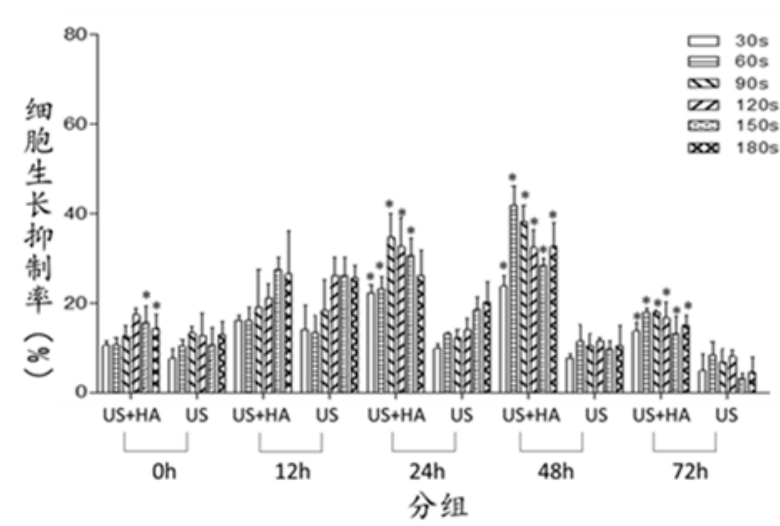

(a)

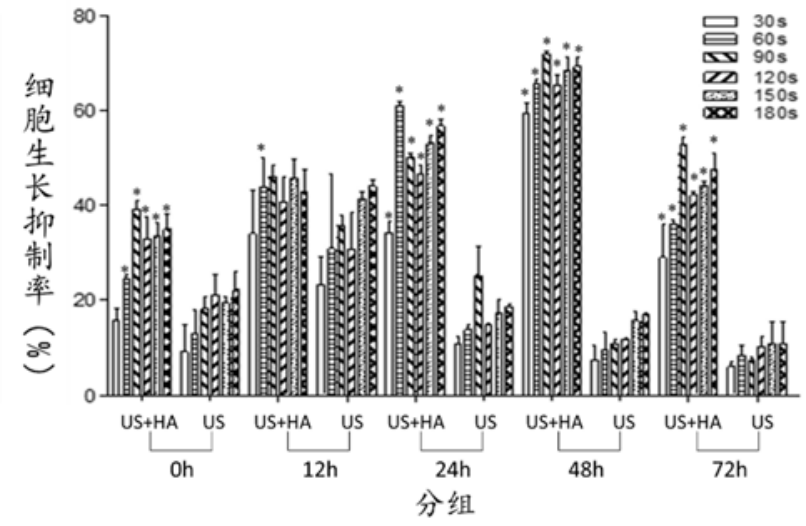

(b)

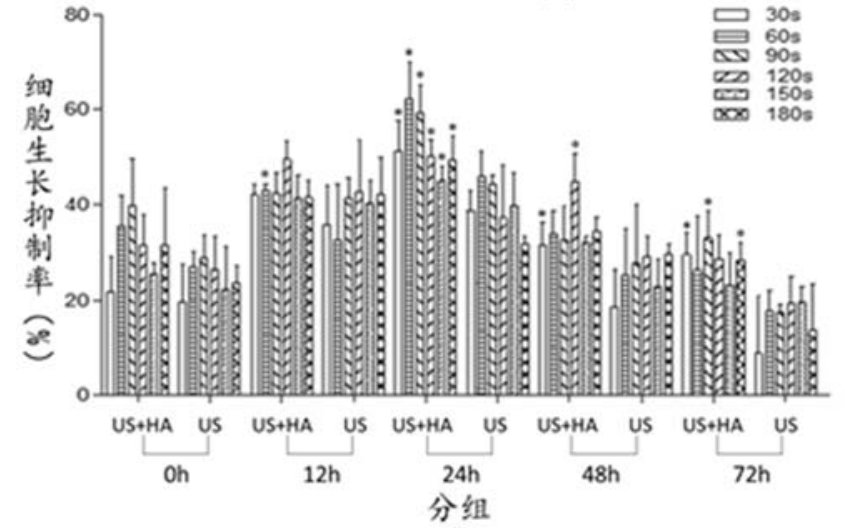

(c)

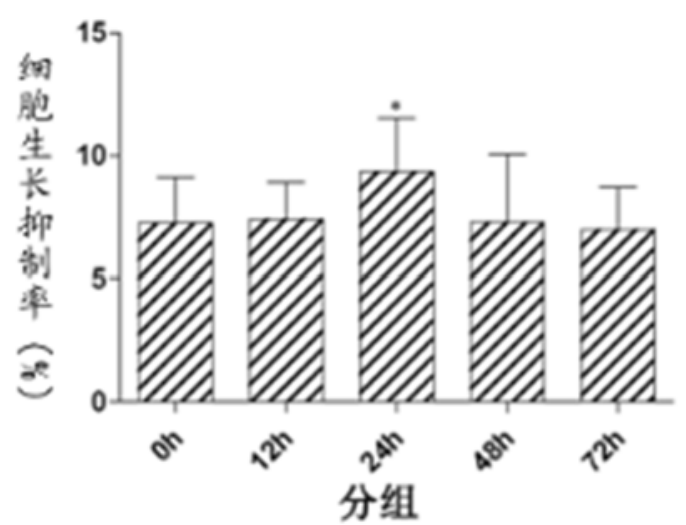

(d)

Fig. 2 The inhibition rate of cells growth were treated by with HA with different US ( $\mathrm{f}=20 \mathrm{kHz}$; $\mathrm{P}=0.1,0.2,0.3 \mathrm{w} / \mathrm{cm} 2 ; \mathrm{t}=30,60,90,120,150,180 \mathrm{~s} ; \mathrm{T}=0,12,24,48,72 \mathrm{~h}$ ). (a) US power 0.1 w/cm2; (b) US power $0.2 \mathrm{w} / \mathrm{cm} 2$; (c) US power $0.3 \mathrm{w} / \mathrm{cm} 2$; (d) HA group

\section{3 cells apoptosis}

From the inhibition rate of cells growth, we selected the best ultrasound parameter $(f=20 \mathrm{kHz}, \mathrm{P}$ $=0.2 \mathrm{w} / \mathrm{cm}^{2}, \mathrm{t}=90 \mathrm{~s}, \mathrm{~T}=48 \mathrm{~h}$ ) to test the cells apoptosis by Annexin V-FITC/PI kit, using flow cytometer. The results were shown in Fig. 3. The cell early apoptosis rate of US+HA, US, HA, and Con group were $(8.300 \pm 1.916) \%,(1.700+0.100) \%,(2.533 \pm 1.531) \%$, and $(1.467 \pm 0.153) \%$, respectively .

The cell late apoptosis rate of US+HA, US, HA, and Con group were $(26.667 \pm 2.281) \%$, $(3.267 \pm 1.858) \%,(4.333 \pm 1.872) \%,(2.167 \pm 0.577) \%$, respectively. The apoptosis rate of HepG2 cells was a statistically significant compared with that of the control group, ultrasound group, and hydroxyapatite group $(P<0.05)$. 


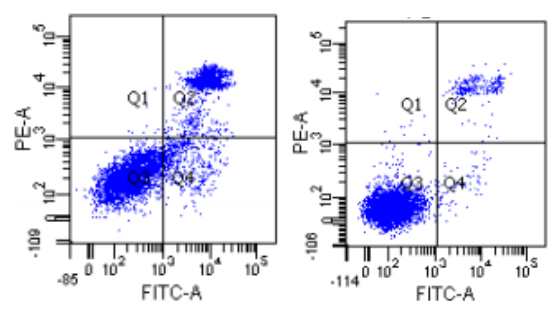

(a)

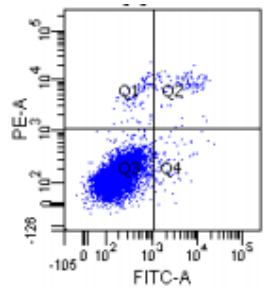

(b)

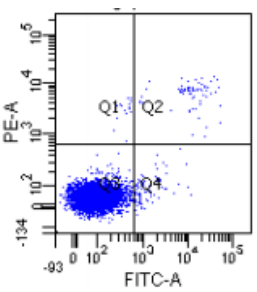

(c)

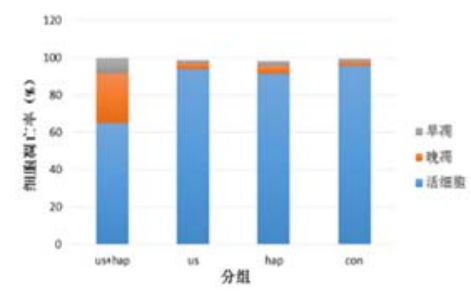

(d)

(e)

Fig. 3 The apoptosis rate of cells were treated by with HA with US $(\mathrm{f}=20 \mathrm{kHz}, \mathrm{P}=0.2 \mathrm{w} / \mathrm{cm} 2, \mathrm{t}=90$, $\mathrm{T}=48$ ). (a) US+HA group; (b) US group; (c) HA group; (d) Con group; (e) The distribution of cell early and late apoptosis rate.

\subsection{Cell Cycle}

After the cell cycle was completed by a series of high phases, cells were finished mitosis to proliferate. From the table 1, we found that US group has not effect on cell cycle compared with Con group. US+HA and HA group were showed G2/M phase block. There was a statistical significance compared with that of the control group, and ultrasound group $(P<0.05)$. The reason may be that HA caused the G2/M phase block. US enhanced the concentration of intracellular HA particles. So it showed obvious $\mathrm{G} 2 / \mathrm{M}$ phase block.

Table 1 The distribution of cell cycle

\begin{tabular}{cccc}
\hline group & G0/G1 (\%) & S (\%) & G2/M (\%) \\
\hline Con & 62.48 & 26.15 & 11.36 \\
US & 61.94 & 25.22 & 12.84 \\
HA & 63.49 & 22.81 & 13.71 \\
US+HA & 61.58 & 19.92 & 18.50 \\
\hline
\end{tabular}

\section{Discussion}

In the study, using MTT test and flow cytometry we detected the inhibitory rate of the cells, cell apoptosis and cell cycle. The results suggest that low-frequency and low-power ultrasound activates Hydroxyapatite inhibited human HepG2 cells proliferation and induces the apoptosis.

Ultrasonic is a kind of propagation form in mechanical vibration energy. It propagates in biological vector which meters the irradiation determined by two factors, the intensity of radiation and the time of irradiation. If the dose of radiation exceeds a certain threshold level, it can produce functional or (and) structural effects for biological medium. Ultrasonic radiation acted on cell membrane which can change the lipid bilayer morphology on the surface of the cell membrane, and then change its permeability, will be in favor of changing the substance of Intracellular and extracellular ${ }^{117,18,19]}$. Ultrasonic enhanced hydroxyapatite into cells, and increased the intracellular HA concentration, then the tumor can be inhabited by low HA concentration. HA can be dissolved at the aid environment, the phosphate radical and calcium ion release of HA, resulting the increase of the intracellular calcium concentration, and induced the tumor cell apoptosis ${ }^{[20,21]}$. Beyond that, HA can affect the function of organelles in cytoplasm, cell cycle block, the inhibition of telomerase activity , mitochondrial function injury, DNA damage, and protein synthesis ${ }^{[22,23]}$. Antitumor Activity and Mechanism were not clear, and it will be expected to be further investigated.

\section{References}

[2]. Chen W, Zheng R, Zhang S, Zeng H, Zuo T, Xia C, Yang Z, He J. Cancer incidence and mortality in China in 2013: an analysis based on urbanization level. Chin J Cancer Res. 29(2017) 1-10.

[3]. Imamura H, Matsuyama Y, Tanaka E, et al. Risk factors contributing to early and late phase intrahepatic recurrence of hepatocellular carcinoma after hepatectomy. J Hepatol. 38(2003)200207. 
[4]. Mashaal Dhir, Alyson A. Melin, et al. A Review and Update of Treatment Options and Controversies in the Management of Hepatocellular Carcinoma. Annals of Surgery. 263(2016)1112-1125.

[5]. Mary Maluccio, Anne Covey. Recent Progress in Understanding, Diagnosing, and Treating Hepatocellular Carcinoma. Ca Cance J Clin. 62(2012) 394-399.

[6]. B.B. Goldberg, R. Gramiak, A.K. Freimanis, Early history of diagnostic ultrasound: the role of American radiologists, AJR Am. J. Roentgenol. 160(1993)189-194.

[7]. Fechheimer M, Boylan JF, Parker S, et al. Transfection of mammalian cells with plasmid DNA by scrape loading and sonication loading. Proc Natl Acad Sci USA. 84(1987) 84638467.

[8]. Cui WC, Tu J, Joo-Ha H,et al. In vivo hyperthermia effect induced by high-intensity pulsed ultrasound. Chinese Physics B. 21 (2012) 074301.

[9]. Thein M, Cheng A, Khanna P, et al. Site-specific sonoporation of human melanoma cells at the cellular level using high lateral-resolution ultrasonic micro-transducer arrays. Biosens Bioelectron. 27(2011) 25-33.

[10]. Lejbkowicz F, Salzberg S. Distinct Sensitivity of Normal and Malignant Cells to Ultrasound in Vitro. Environmental Health Perspectives. 105(1997)1575-1578.

[11]. Fu Q, Hong Y, Liu X, Fan H, Zhang X. A hierarchically graded bioactive scaffold bonded to titanium substrates for attachment to bone. Biomaterials. 32(2011) 7333-7346.

[12]. Fernandez JM, Molinuevo MS, Cortizo MS, Cortizo AM. Development of an osteoconductive PCL-PDIPF-hydroxyapatite composite scaffold for bone tissue engineering. J Tissue Eng Regen Med. 5(2011) e126-e135.

[13]. USKOKOVIĆ and DESAI, et al. In Vitro Analysis of Nanoparticulate Hydroxyapatite/Chitosan Composites as Potential Drug Delivery Platforms for the Sustained Release of Antibiotics in the Treatment of Osteomyelitis. J Pharm Sci. 103(2014) 567-579.

[14]. M. Zhang, A. Ishii, N. Nishiyama, S. Matsumoto, T. Ishii, Y. Yamasaki, K. Kataoka, PEGylated calcium phosphate nanocomposites as smart environment-Sensitive carriers for siRNA delivery, Adv. Mater. 21(2009) 3520-3525.

[15]. Shipu Li, Effects of hydroxyapatite ultrafine powder on colony formation and cytoskeletons of MGC-803 cell. Bioceramics. 9(1996) 225-227.

[16]. R. Meena, K.K. Kesari, M. Rani, R. Paulraj, Effects of hydroxyapatite nanoparticles on proliferation and apoptosis of human breast cancer cells (MCF-7).J. Nanopart. Res. 14(2012) 712.

[17]. Yuan Y, Liu C, Qian J, Wang J, Zhang Y. Size-mediated cytotoxicity and apoptosis of hydroxyapatite nanoparticles in human hepatoma HepG2 cells. Biomaterials. 31(2010) 730-740.

[18]. Tyler W J, Tufail Y, Finsterwald M, et al. Remote Excitation of Neuronal Circuits Using LowIntensity, Low-Frequency Ultrasound. PLoS One. 3(2008) e3511.

[19]. Boland L M, Drezewiecki M M. Polyunsaturated Fatty Acid Modulation of Voltage-Gated Ion Channels. CELL BIOCHEMISTRY AND BIOPHYSICS. 52(2008) 59-84.

[20]. Kubanek J, Shi J, Marsh J, et al. Acoustic tweezing cytometry for live-cell subcellular modulation of intracellular cytoskeleton contractility. Scientific Reports. 3(2013) 2176.

[21]. Qing F, Wang Z, Hong Y, et al. Selective Effects of Hydroxyapatite Nanoparticles on Qsteosarcoma Cells and Osteoblasts. Journal of Materials Science. Materials in Medicine. 23(2012) 2245-2251.

[22]. Motskin M, Wright D, Muller K, et al. Hydroxyapatite Nano and Microparticles: Correlation of Particle Properties with Cytotoxicity and Biostability. Biomaterials. 30(2009) 3307-3317.

[23]. Chu S H, Karri S, Ma Y B, et al. In Vitro and in Vivo Radiosensitization Induced by Hydroxyapatite Nanoparticles. Neuro-Oncology. 15(2013) 880-890.

[24]. Jin P, Chen Y, Zhang S B, et al. Interactions between Al12X(X=Al, C, N and P) Nanoparticles and DNA Nucleobases/Base Pairs: Imlications for Nanotoxicity. Journal of Molecular Modeling. $18(2012)$ 559-568. 